\title{
Reconfigurable radiation pattern antennas in $\mathrm{mm}$-waves
}

\author{
Olivier Lafond, M. Caillet, B. Fuchs and M. Himdi \\ IETR, University Of Rennes 1 \\ France
}

\section{Introduction}

Far-field radiation pattern control has strong potential in smart antennas, wireless communications and radar. Typical planned applications include multipath fading and interference mitigation, data rate and coverage enhancement, etc. For implementing these functionalities, either switch beam or reconfigurable Half-Power Beam-Width (HPBW) antennas are required. In particular, short range and "Stop and Go" radars are deployed by car industry (Wenger, 2005) and operate in millimeter wave frequency bands. Multi-beam antennas have been studied extensively and realized using diverse techniques. Butler (Butler \& Lowe, 1961) and Blass (Blass, 1960) matrices are complex feed networks composed of couplers and phase shifters which provide phase difference between radiating elements to steer a beam in a given direction. Rotman lens (Rotman \& Turner, 1963), (Schulwitz \& Mortazawi, 2006) is a quasi-optical system based on a cavity limited by two arcs. Inputs and outputs are placed along the two arcs and phase difference between the output ports is achieved by microwave propagation through the cavity. Micro-Electro-Mechanical Systems (MEMS) have been employed either to mechanically orientate an array (Baek et al., 2003) or to switch between two antennas having a different beam angle (Cetiner et al., 2003). Lens array (Popovic \& Popovic, 2002) and dielectric lens (Wu et al., 2001) are other interesting concepts used to design multi-beam antennas by moving the feed at the back of the lens.

In this chapter, the authors present different antenna concepts to obtain reconfigurable radiation pattern capability in millimeter waves.

- $\quad$ First, multibeam antennas are demonstrated based on Butler matrices at 24 and 60 GHz. Passive and active designs are considered and manufactured prototypes are presented to show radiation patterns and gain results.

- Furthermore, reconfigurable Half Power BeamWidth (HPBW) antennas are shown. The objective is to modify the directivity of an array by changing the number of fed patches. Passive and active prototypes have been fabricated to prove the reconfigurability concept at $24 \mathrm{GHz}$.

- Finally, a new technique is presented to shape the radiation pattern of an antenna to achieve directive or sectorial beams. In this case, the antenna design is based on an inhomogeneous lens (Maxwell Fish-Eye lens) fed by several sources. 
In addition, the authors designed element array in millimeter waves using multilayer technology to separate radiating elements and feeding lines, in order to avoid spurious radiation from lines and to keep good performances in terms of sidelobe and cross polarization levels. Details of the multilayer technology are given in the first part of this chapter.

\section{Multibeam antenna based on Butler Matrix}

The Butler matrix (Butler \& Lowe, 1961) allows to turn an antenna array into a multibeam system. In addition, the Butler matrix and microstrip technologies are both suitable for the use of active devices to design active antenna. The Butler matrix includes hybrid couplers $\left(3 \mathrm{~dB}, 90^{\circ}\right)$, passive phase shifters and cross-over elements in order to feed the different radiating elements with the appropriate phases. However, in millimeter waves, low efficiency is often obtained due to metallic and dielectric losses of the printed lines.

Moreover, printed multilayer technologies are desirable to avoid spurious radiation from the lines of the matrix (Lafond \& Himdi, 2002). Based on these facts, multilayer technology has been considered in the proposed designs to achieve neat radiation patterns.

\subsection{Multilayer Technology}

In this part, details are provided regarding the used multilayer technology. It consists of two different substrate layers separated by a thick ground plane. The first microstrip line printed on the bottom layer couples to the second one, printed on the top substrate, via a slot engraved in the ground plane. The second line is electromagnetically coupled to the slot. In this case, this design is named microstrip line - slot - microstrip line transition (Fig. 1a). Another option is to excite a microstrip patch through an aperture slot (Fig. 1b). These different multilayer feeding techniques have been tested up to $60 \mathrm{GHz}$ (Lafond et al., 1999), (Lafond et al., 2002), (Lafond et al., 2005).
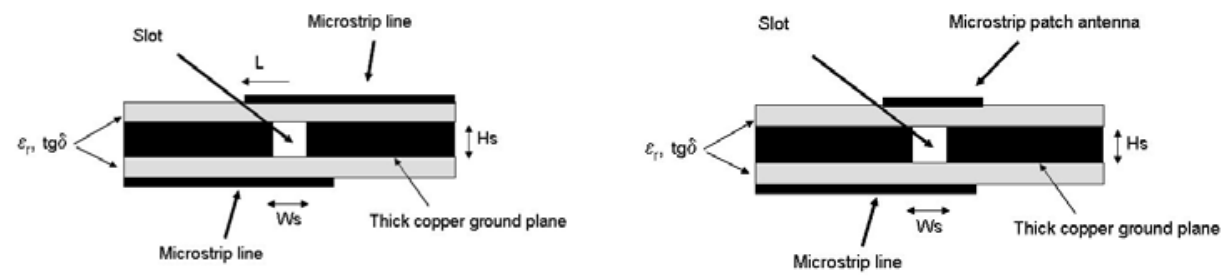

Fig. 1. (a) Microstrip line - slot - microstrip line transition, (b) Aperture coupled patch antenna

In millimeter waves, thin substrates $(0.1$ to $0.2 \mathrm{~mm})$ are usually used to avoid surface wave losses, and to achieve good efficiency when antennas are designed. Then, the manufactured prototypes are often soft or breakable. To solve this problem, a thick ground plane $(0.2 \mathrm{~mm}$ to $0.5 \mathrm{~mm}$ ) is added between the two substrate layers. Moreover, this thick ground plane is appropriate to active components (MMIC ...). The thickness of the ground plane has to be taken into account because it reduces coupling trough the slot. Thus, these multilayer 
technologies give the possibility to design active antennas by separating radiating elements from circuits and feeding lines.

\subsection{Passive Butler matrix and printed array at $60 \mathrm{GHz}$}

For indoor communication systems at $60 \mathrm{GHz}$, the link between transmitter and receiver can be cut even by human body if directive antennas are used. Thus, multibeam antennas can be a solution to avoid these failures. In this part, a passive Butler matrix with four beams is used to feed a four patch array. Each input of the matrix allows to steer one beam. Each beam is achieved by applying a phase shift between the patch antennas. This phase shift is obtained thanks to the butler matrix which is composed of hybrids and phase shifters. But, to feed the patches with appropriate phases, the microstrip lines must be crossed inside the matrix. To realize these crossings, a cross-over hybrid is used in the Butler matrix system (Fig. 2a). For this design, aperture coupled patches are optimized and are connected to the outputs of the Butler matrix via coupling slots. RT 5880 Duroid substrate $(\mathrm{h}=0.127 \mathrm{~mm}$ and $\left.\varepsilon_{\mathrm{r}}=2.23\right)$ is used for both layers of the prototype. The four configurations under consideration (F1 to F4) reveal tilt angles of $\pm 15^{\circ}$ and $\pm 45^{\circ}$. The element spacing is $0.5 \lambda_{0}$ to maintain low side lobe level, whatever the tilt angle. The actual matrix and antenna array are presented in Fig. $2 b$ wherein the two distinct layers are shown. In addition, the return loss has been measured for each configuration (F1 to F4) in order to check that all configurations are properly matched (Fig. 3). The return loss is greater than $10 \mathrm{~dB}$ around 60 GHz. The measured radiation patterns are presented in Fig. 4 for all configurations. Good results can be observed in terms of tilt angle and side lobe level. These results prove that achieving good performance with a multibeam antenna is possible in mm-waves. Regarding efficiency, its value is close to $40 \%$ due to metallic and dielectric losses in the cross-over and feeding network.

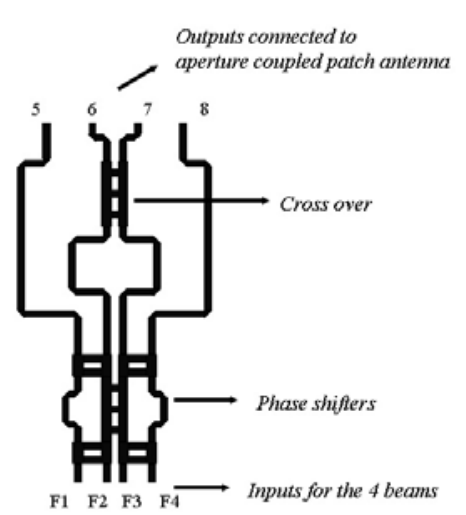

(a)

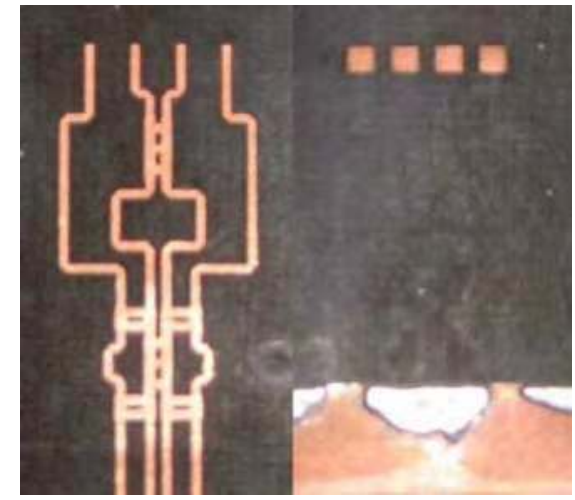

(b)

Fig. 2. (a) Butler Matrix, (b) Butler Matrix and array using multilayer technology 


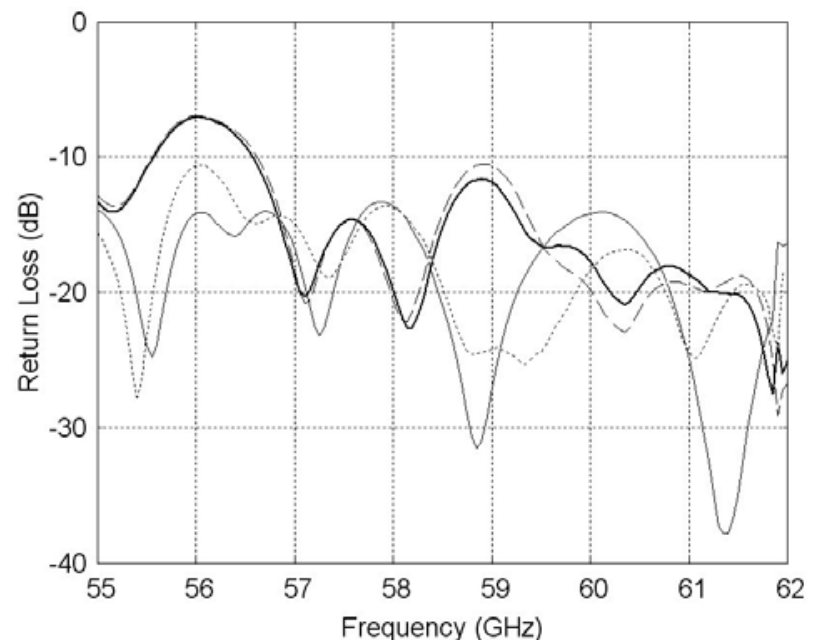

Fig. 3. $4 \times 4$ Butler-matrix: return loss (dB) of each input (F1 to F4)

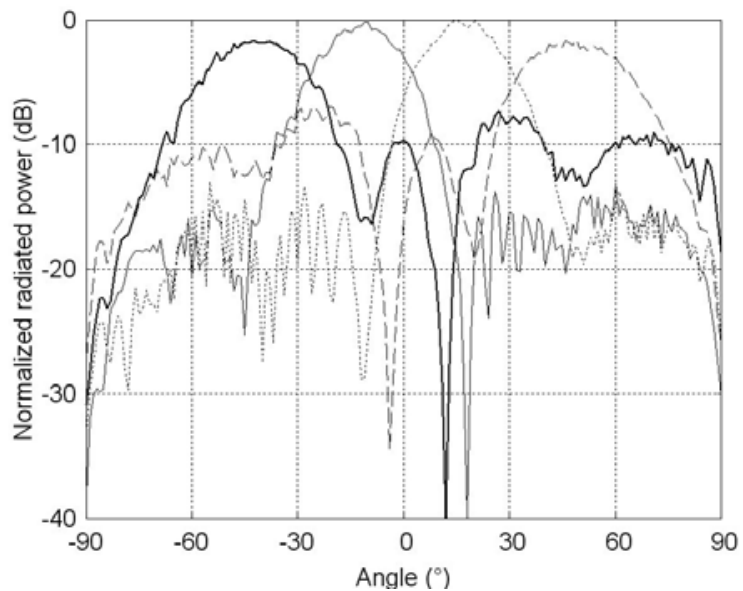

Fig. 4. $4 \times 4$ Butler-matrix: radiation patterns at $60 \mathrm{GHz}$ for all configurations

This first design is a passive one, but a complete prototype must include active devices to select the beam. Then, an active feeding system has to be designed to achieve this function. An active Butler matrix is presented in Section 2.3 at $24 \mathrm{GHz}$. Details about switches, matching technique and measured radiation patterns are provided.

\subsection{Active Butler matrix and printed array at $24 \mathrm{GHz}$}

An active switch beam antenna based on Butler Matrix includes a switching network. The objective of the switching network associated to the Butler matrix (Fig. 5) is to select one beam among four. This means that only one switch will be ON and the other ones OFF at a given time. The main issue in the conception of this antenna is the design of the feed network in front of the matrix to maintain a good matching for all configurations. But before 
to explain the technique used to match the active antenna, the switch configuration must be chosen. Many technologies exist for RF switch design. The most common is based on semiconductors (Macom), (Rebeiz, 2003) and electromechanical switches (Quinstar). The latter ones are expensive, hardly integrable and have low switching speed. For MEMS, the isolation is better than semiconductors but, again, the switching speed is low and internal parasitic radiation could affect the signal integrity. Based on these facts and considering that discrete components are available and cheaper, the semiconductor technology has been selected to design a switch. In addition, discrete components can be easily integrated with the microstrip double layer technology selected to develop the prototypes. Two types of discrete components are useful to design switches: PIN diodes and transistors. Switches based on PIN diodes have insertion losses, while switching circuits using transistors have on the opposite gain. Moreover, transistors have a better isolation than diodes, thus a FET transistor has been retained.

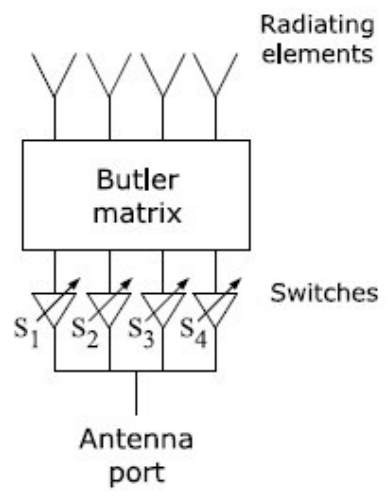

Fig. 5. Butler matrix and active feeding system to select one beam among four

A receiving antenna is considered here, thus a variable gain amplifier has been designed with control on the drain bias. The configuration of this switch amplifier has been optimized to minimize the Noise Figure (NF). Hence, when the switch is in the ON state, the gain should be positive, the input return loss equals to $\Gamma_{\mathrm{OPT}}$ to minimise the $\mathrm{NF}$, and the output return loss matched to $50 \Omega$. Besides, as explained in (Caillet, 2006), the matching concept of the antenna is based on an open circuit impedance of the "OFF" switch is in the OFF state, associated with design of path lengths in the feed network at a multiple of $\lambda \mathrm{g} / 2$. Thus, each junction will see open circuit(s) from the "off" switch output(s).

Characterization of the transistor's S-parameters is required because both ON and OFF states' S-parameters are used to meet the constraints. A TRL calibration method has been used to obtain the scattering parameters into two planes at $1 \mathrm{~mm}$ from transistor's grid and drain. The S-parameters of a NEC NE3210s1 transistor have been characterized with $\mathrm{V}_{\mathrm{DS}}=$ $0 \mathrm{~V}$ (OFF state) and $\mathrm{V}_{\mathrm{DS}}=2 \mathrm{~V}\left(\mathrm{ON}\right.$ state) and, $\mathrm{V}_{\mathrm{GS}}=0 \mathrm{~V}$ in both states. Parallel stubs have been placed at the input and output of the transistor and microstrip lines' impedances and lengths have been optimized to match the constraints. This switch, optimized on a RO3003 substrate ( $\varepsilon r=3$ and $\mathrm{h}=0.127 \mathrm{~mm}$ ), allows to have a $3.5 \mathrm{~dB}$ gain and close to $20 \mathrm{~dB}$ in term of isolation. In the OFF state, the output impedance is not a real open circuit but higher than $260 \Omega$. Combining this switch with the matching network, an active Butler matrix has been 
designed and feed a four printed patch array at $24 \mathrm{GHz}$. A multilayer technology has been used with RO3003 substrate for the active layer (Fig. 6a) and RT 5880 substrate ( $8 r=2.2$ and $\mathrm{h}=0.127 \mathrm{~mm}$ ) for the radiating elements (Fig. 6b). The patches are fed by microstrip line slot - microstrip line transition. The slots are etched in a $0.2 \mathrm{~mm}$ thick ground plane.

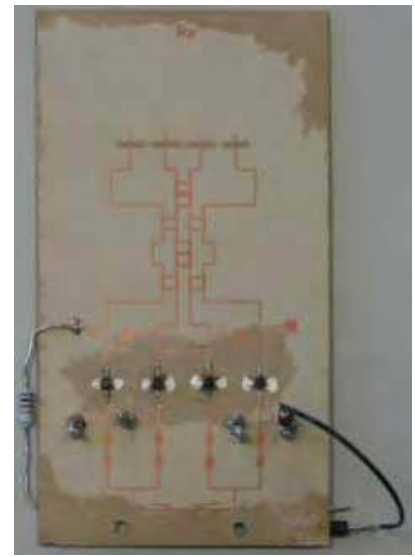

(a)

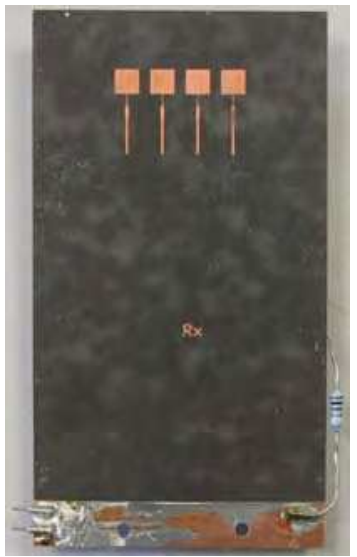

(b)

Fig. 6. (a) Active Butler matrix on RO3003 substrate, (b) Radiating element array fed by microstrip line - slot - microstrip line.

Acceptable matching results have been obtained by measurement (Fig. 7). S11 is close to -12 $\mathrm{dB}$ for all configurations at $23.9 \mathrm{GHz}$. Concerning radiation patterns (Fig. 8), the tilt angles are $-14^{\circ}, 40^{\circ},-45^{\circ}$ and $13^{\circ}$. In Fig. 8 , all the radiation patterns have been normalized but the gain is not the same for all configuration but equals to $10 \mathrm{~dB}, 8 \mathrm{~dB}, 8.3 \mathrm{~dB}$ and $11.5 \mathrm{~dB}$ respectively. These gains correspond to $50 \%$ efficiency for the active antenna. The gain decreases when the tilt angle increases. Cross polarization levels are in the vicinity of $-17 \mathrm{~dB}$ for all configurations. Back radiation level is close to $-10 \mathrm{~dB}$ and is most probably due to slots and stubs contributions.

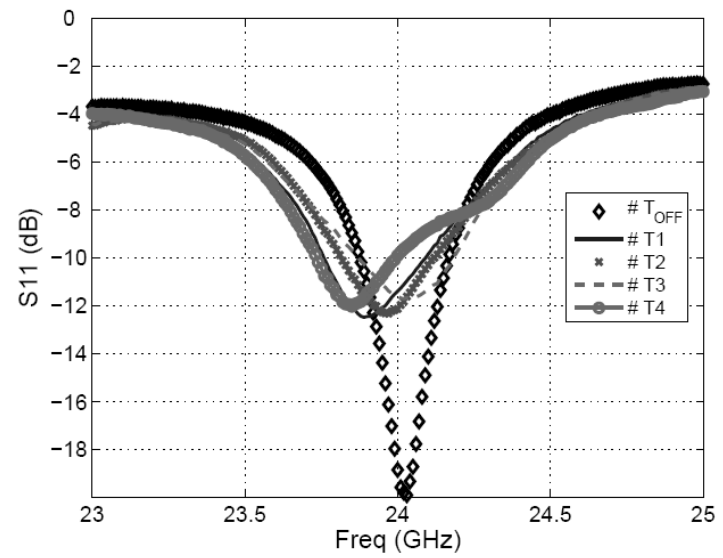

Fig. 7. Active Butler matrix and array - Measured S11 results for all configurations 


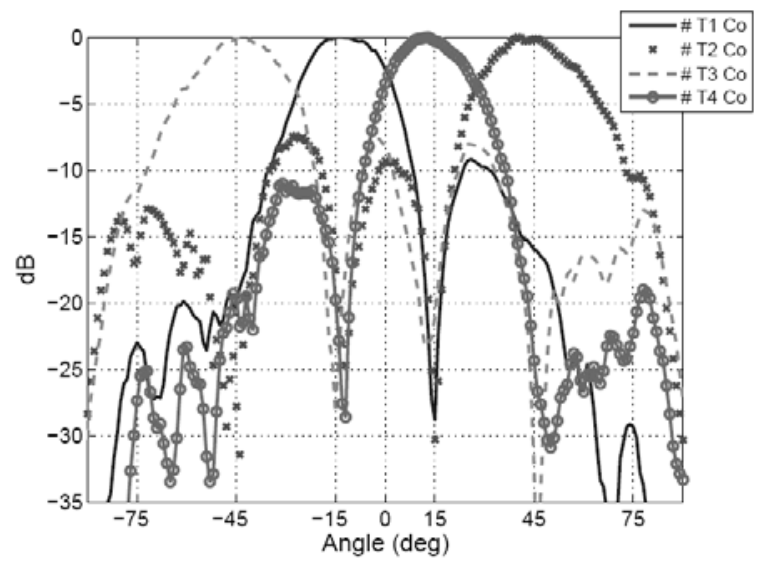

Fig. 8. Active Butler matrix and array - Measured radiation patterns for all configurations

All these results show the potential of the Butler matrix system for the design of active multibeam antennas in millimetre waves. Nevertheless, metallic and dielectric losses in the feeding network of the Butler matrix induce a quite low efficiency if printed technologies are used. Other technologies like Substrate Integrated Waveguide could be investigated to reduce the losses of such systems.

\section{Half-power beam width reconfigurable antenna}

Tunable half-power beam width (HPBW) antennas are of interest for automotive radars at 24 and $77 \mathrm{GHz}$. Indeed, these antenna systems allow to adjust the directivity of the antenna to have either a narrow beam for long range radar application, or a wide beam for short range radar application. This functionality can be obtained using an antenna array by changing the number of fed sources in the array. The feed network of the array is composed of switches associated to each radiating element (Fig. 9(a)). The HPBW is determined by the number of ON switch(es). In this case, the input impedance is varying with the number of switches in the ON state. Thus, the feeding line network has to be optimized to guarantee a low return loss whatever the fed sources number in the array (Fig. 9 (b)).

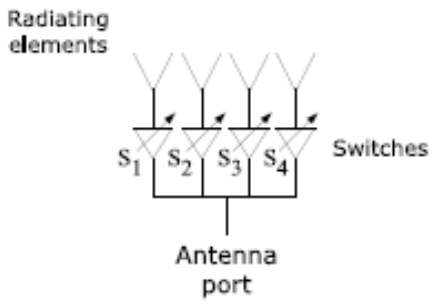

(a)

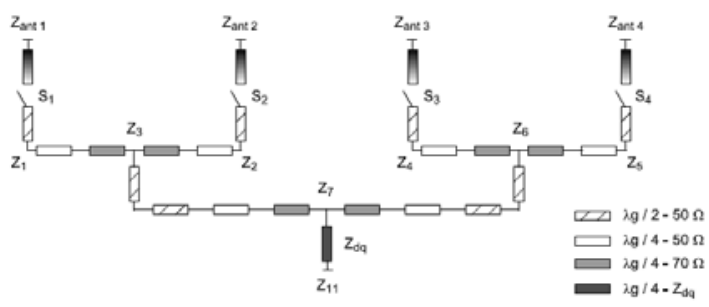

(b)

Fig. 9. (a) Active HPBW antenna concept, and (b) Unconventional feeding network 


\subsection{Matching technique}

As the input impedance will change with the number of fed sources, an unconventional feeding network has been defined to match this reconfigurable antenna. Based on the Butler matrix antenna feed network described in Section 2.3, it is possible to change the value of some quarter wavelength transformers to translate the impedances of all configurations in a Voltage Standing Wave Ratio (VSWR) lower than 2. $70.71 \Omega$ quarter wavelength lines are placed around each tee junction to have a $50 \Omega$ input impedance when all radiating elements are fed. An additional quarter wavelength line $\mathrm{Zdq}$ is disposed between the antenna port and the lower tee junction. The input impedance is computed using the following equation:

$$
Z_{11}=Z_{\mathrm{dq}}^{2} \cdot \frac{Z_{1} Z_{2}\left(Z_{4}+Z_{5}\right)+Z_{4} Z_{5}\left(Z_{1}+Z_{2}\right)}{4 Z_{1} Z_{2} Z_{4} Z_{5}}
$$

With $\mathrm{Zp}=50 \Omega, \mathrm{p}=1,2 . .5$, if the switch is in the ON state With $\mathrm{Zp}=\infty, \mathrm{p}=1,2 . .5$, if the switch is in the OFF state.

When $\mathrm{Zdq}=50 \Omega$, the obtained impedances are varying from 50 to $200 \Omega$ (D4 to D1 configurations). These impedances are shown on the smith chart in Figure 10. The impedance center $(\mathrm{Zb})$ is then:

$$
\mathrm{Z}_{\mathrm{b}}=\sqrt{\mathrm{Z}_{\min } \cdot \mathrm{Z}_{\max }}=100 \Omega
$$

Based on this facts, one solution to match the reconfigurable antenna whatever the fed sources number is to modify the $\mathrm{Zdq}$ value to obtain $\mathrm{Zb}=50 \Omega$. Thus, the antenna matching will be optimal for $\mathrm{Zdq}=70.7 \Omega$. This new matching technique can be generalized for larger arrays and explained in (Caillet, 2006).

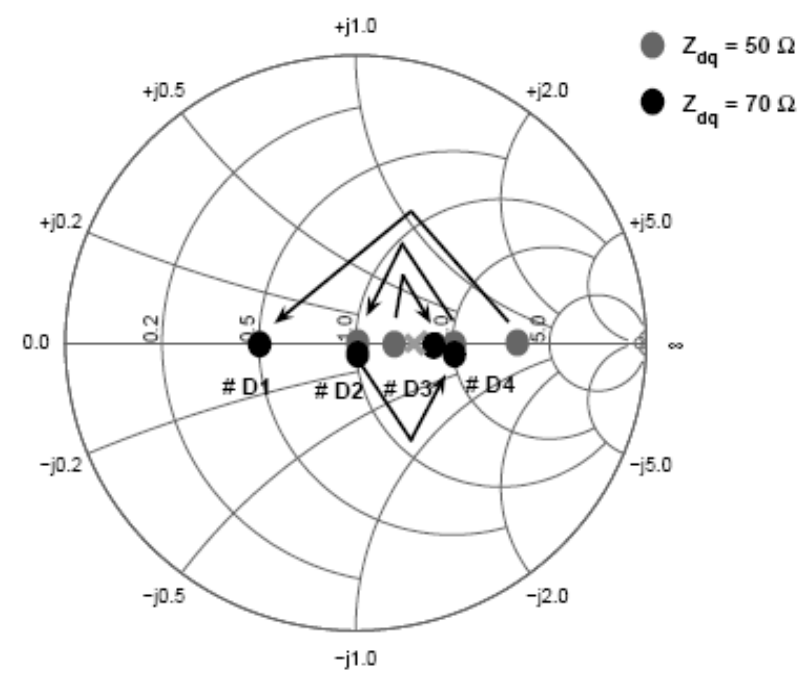

Fig. 10 . Input impedances for D1 to D4 configurations 


\subsection{Passive HPBW reconfigurable antenna at $24 \mathrm{GHz}$}

Using the matching concept described in Section 3.1, a passive HPBW antenna has been designed and manufactured for characterization. The developed prototype is shown in Fig. 11 for the feeding network printed on RO3003 substrate $(\varepsilon r=3$ and $h=0.127 \mathrm{~mm})$ and for the patch array printed on RT Duroid $5880(\varepsilon r=2.2$ and $h=0.127 \mathrm{~mm})$. In this case, a multilayer technology is used and patches are fed by electromagnetic coupling with microstrip line - slot - microstrip line transitions.

This antenna has been designed and simulated using Ansoft Designer (feeding network) and CST Microwave Studio (global antenna). This passive prototype has been built by replacing switches by gaps. The switching process used during measurements consists in soldering gap(s) to have ON-state switch(s). The return loss (Fig. 12) is greater than $20 \mathrm{~dB}$ at $24.15 \mathrm{GHz}$ for all configurations (D1 to D4). These results validate the new matching technique described earlier. The measured radiation patterns are shown in Fig. 13 for the four configurations. According to the results, measured half-power beam widths are $71^{\circ}$ when one patch is fed, $36^{\circ}$ when two patches are fed, $25^{\circ}$ when three patches are fed, and $20^{\circ}$ with four patches at $24.15 \mathrm{GHz}$. The measured gains are 5.4, 7.6, 10.0, and $12.4 \mathrm{~dB}$, respectively. The levels of the cross-polarization component are lower than $-15 \mathrm{~dB}$.

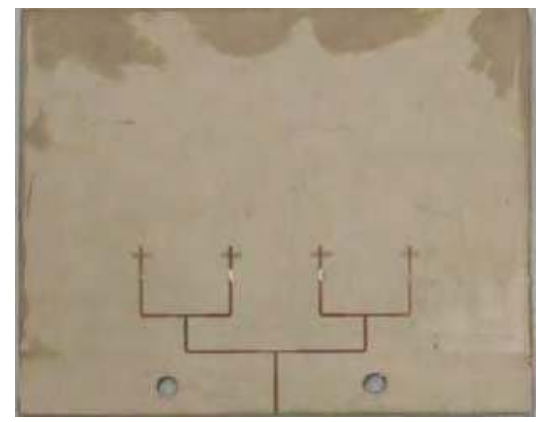

(a)

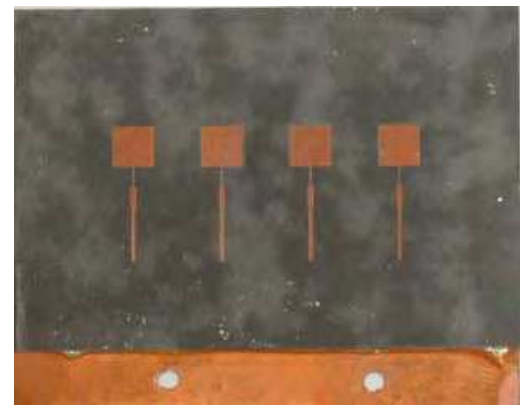

(b)

Fig. 11. Passive HPBW antenna - (a) feeding network and (b) patch array

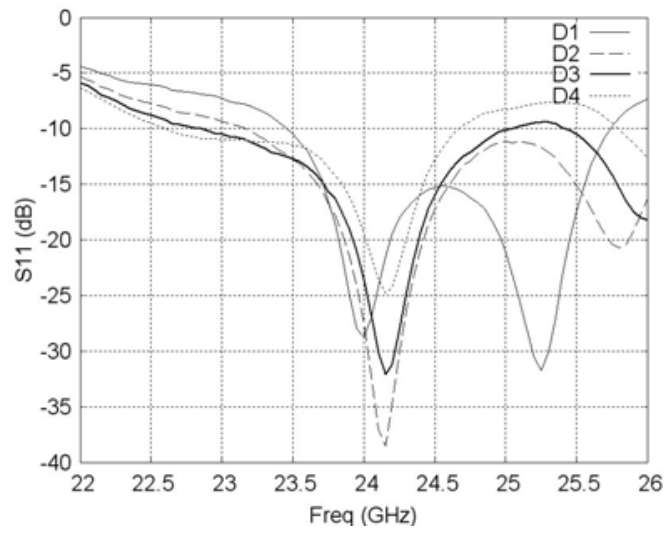

Fig. 12. Passive HPBW antenna - Measured S11 results for all configurations 


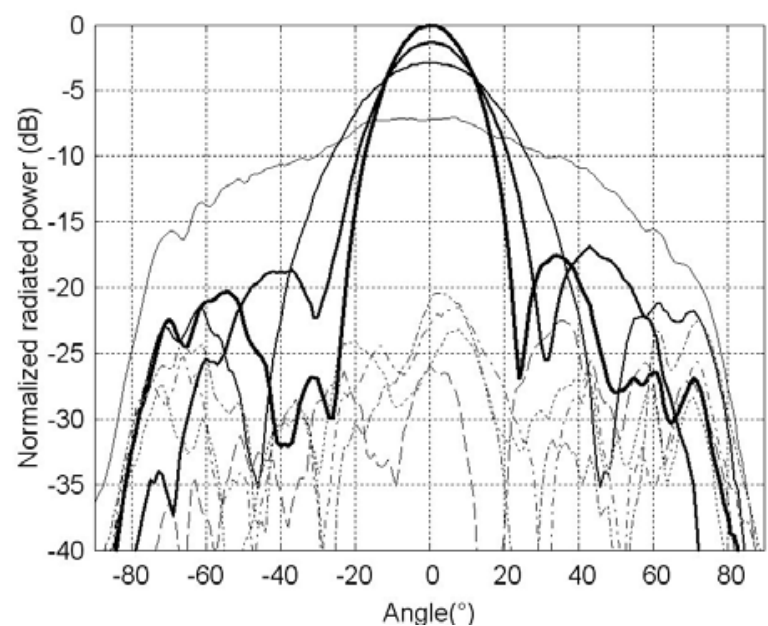

Fig. 13. Passive HPBW antenna - Measured radiation patterns (co and cross polarization) for all configurations

\subsection{Active HPBW reconfigurable antenna at $24 \mathrm{GHz}$}

An active HPBW reconfigurable has been designed and measured at $24 \mathrm{GHz}$. The same substrates are used (RO 3003 for active layer and Duroid 5880 for radiating layer). Thanks to the used multilayer technology (Fig. 14), the active switches are connected to the feeding line network. The active switch is the same than for Butler matrix design, based on a LNA amplifier configuration (section 2.3). The manufactured prototype is presented in Fig. 15 for both layers.

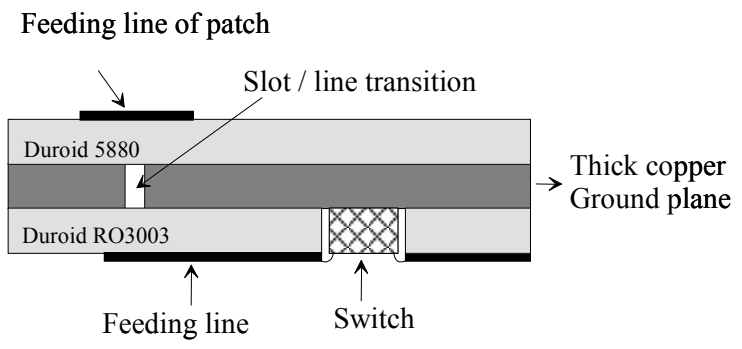

Fig. 14. Active HPBW antenna - Multilayer technology and switches' structure

The directivity depends of the number of fed patches and is respectively equals to $7.3,11.2$, 13.6 and $15.1 \mathrm{dBi}$ in simulation (D1 to D4 configurations). The measured S11 results are given in Fig. 16 and show a good matching at $23.9 \mathrm{GHz}$ even if only $-8 \mathrm{~dB}$ is achieved for the D4 configuration. The measured radiation patterns are shown in Fig. 17 for the same configurations. The measured gains are respectively equal to $9 \mathrm{~dB}, 12.3 \mathrm{~dB}, 15.3 \mathrm{~dB}$ and 16.4 $\mathrm{dB}$. These results are higher than the simulation predictions, but it could be explained by a higher than predicted active switch power gain. 

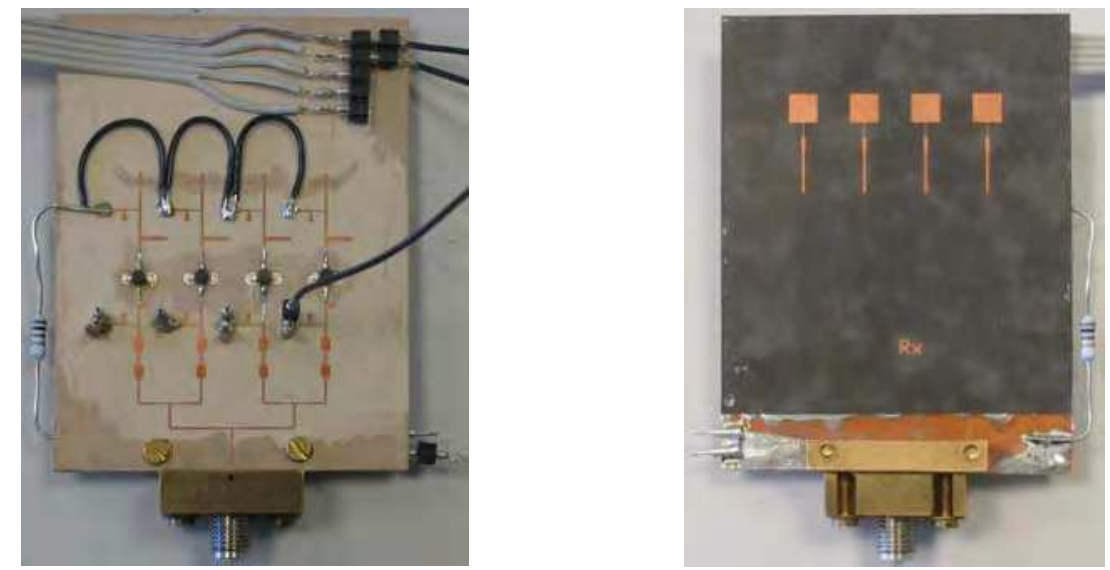

Fig. 15 . Active HPBW antenna - Photos of the manufactured prototype

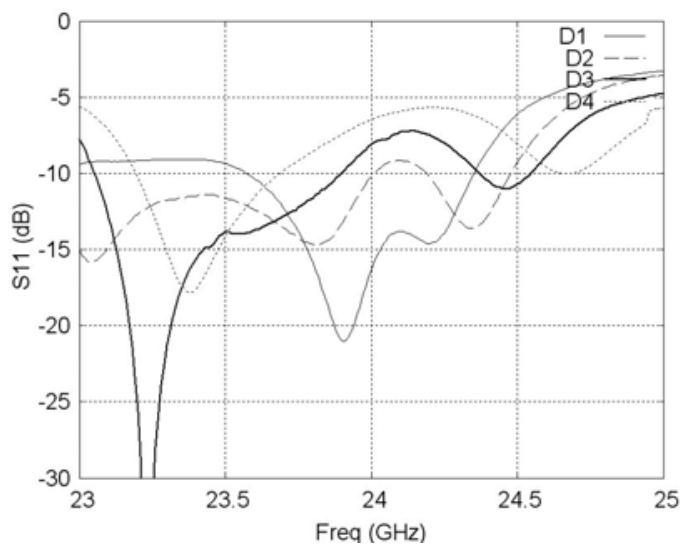

Fig. 16. Active HPBW antenna - Measured S11 results for all configurations

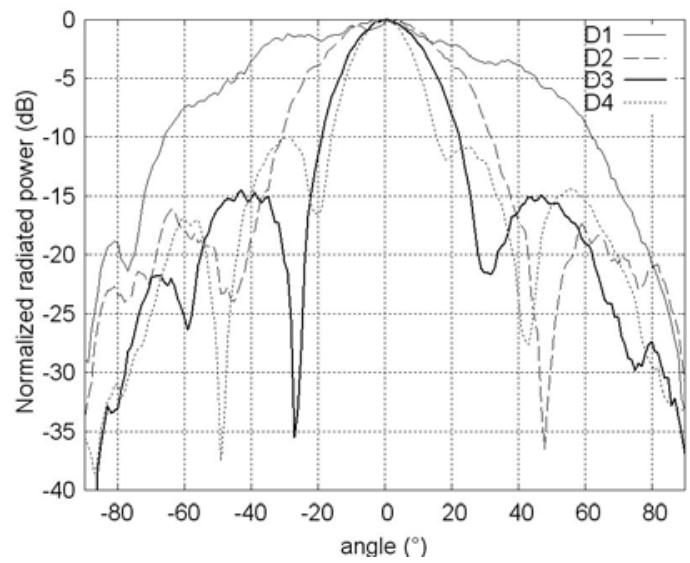

Fig. 17. Active HPBW antenna - Measured radiation patterns for all configurations 
An active tunable HPBW printed antenna has been demonstrated at $24 \mathrm{GHz}$. This prototype allows to vary the half-power beam width of the antenna by changing the number of fed patches in the array. To achieve this result, the design of a switch based on a FET transistor has been proposed. The matching of this antenna is obtained whatever the number of fed patches by modifying the characteristic impedance of a quarter wavelength transformer. However, the design of the tunable HPBW does not allow beam steering. An innovative principle based on sources array and lens is presented in the following section to have radiation pattern shaping capabilities.

\section{Inhomogeneous lens and sources array to shape the beam}

\subsection{Introduction about inhomogeneous lenses}

Inhomogeneous lenses have focusing and beam forming capabilities. In such lens, the refraction index $\mathrm{n}(\mathrm{r})$ inside the lens follows a radial distribution. The most known example is the 'Luneburg' lens (Luneburg, 1944), but we investigated, since a few years, another kind of inhomogeneous lens named Half Maxwell Fish Eye (HMFE) (Lafond et al., 2007). The refraction index law is given by:

$$
\mathrm{n}(\mathrm{r})=\frac{2}{1+\mathrm{r}^{2}} \quad \begin{aligned}
& \text { where } r \text { is the normalized } \\
& \text { radial position. }
\end{aligned}
$$

With this particular law inside the lens, a plane wave is achieved at the middle of the lens and then a hemispherical lens can be used (Fig. 18). It is very interesting to reduce the lens dimension compare to a classical Luneburg lens.

The dielectric constant inside the lens ranges between $1(r=1)$ and $4(r=0)$. To approximate the continuous gradient index law, several concentric homogeneous dielectric shells are assembled and their characteristics have been optimized (Fuchs et al., 2006), (Fuchs et al., 2007, a). The radius and dielectric constant of shells are chosen to optimize the directivity when the lens is fed by only one source (Fig.19). It is known that if only one source feeds the HMFE lens, a directive pattern is achieved.
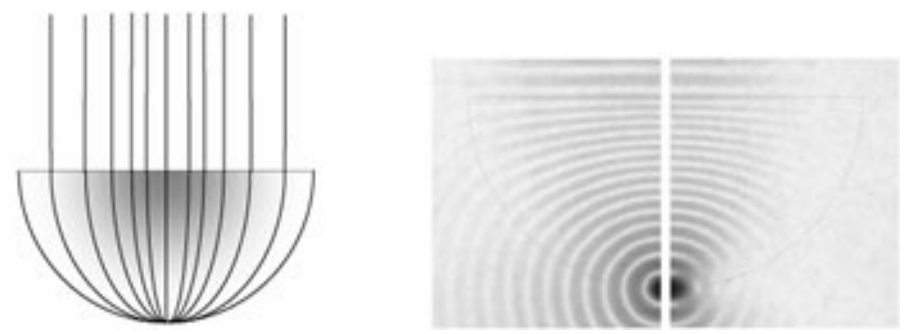

Fig. 18. Plane wave with an hemispherical HMFE lens 


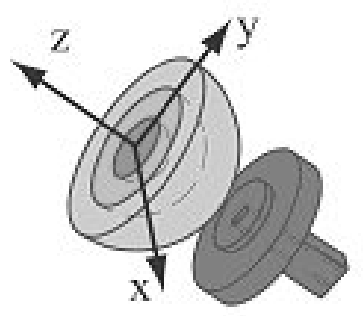

Fig. 19. HMFE lens fed by a WR10 open-ended waveguide

\subsection{Focusing capability with an HMFE lens}

An HMFE lens experimental prototype has been manufactured using a 9-shells $60 \mathrm{~mm}$ diameter HMFE lens (Fig. 20) fed by a WR10 open-ended waveguide. The measured radiation pattern in both $\mathrm{E}$ and $\mathrm{H}$ planes are compared to the computed radiation pattern (mode matching technique) (Fuchs, 2007) at $77 \mathrm{GHz}$ (Fig. 21). For this antenna, a 28.5dB measured gain is achieved.

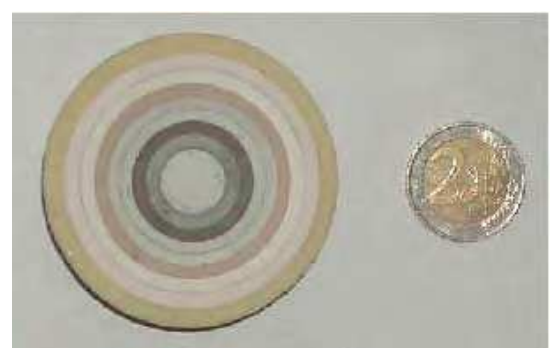

Fig. 20. A 9 - shells $60 \mathrm{~mm}$ diameter HMFE lens
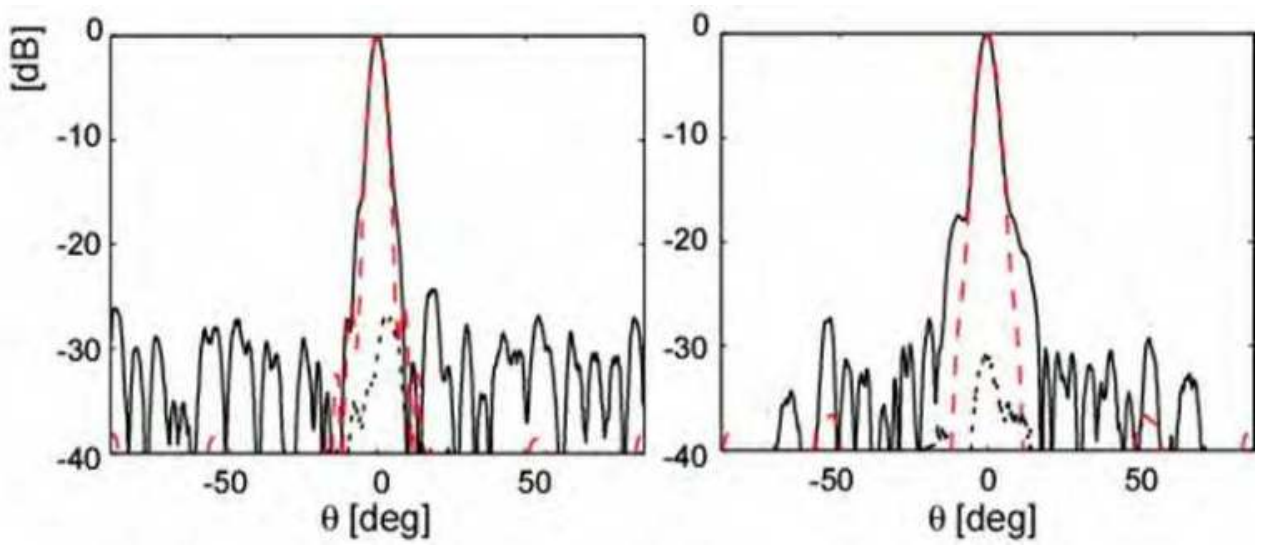

Fig. 21. A 9 - shells 60mm diameter HMFE lens H plane radiation pattern (left), E plane radiation pattern (right) 


\subsection{Beam scanning capability with an HMFE lens}

In our case, the lens gradient index is approximated by assembling several concentric homogeneous dielectric shells. Then, the law is not perfect and a focal spot appears under the lens. Thus, if the feeder moves under the lens, it has been shown that it was possible to obtain beam scanning capability (Fuchs et al. 2007, b). To validate this principle, the 9-shells $60 \mathrm{~mm}$ diameter has been fed by an open-ended waveguide at $77 \mathrm{GHz}$. To translate the feed, a mechanical system with a high precision has been added (Fig. 22).

Measurements have been done (Fig. 23) at $77 \mathrm{GHz}$ to show this capability in the $\mathrm{H}$ plane of the antenna. The 9-shell 60mm diameter HMFE lens is always fed by a WR10 open-ended waveguide. It is possible to steer the beam up to $12^{\circ}$ when the feeder offset equals $5 \mathrm{~mm}$. It is possible to increase this tilt angle but the side lobe level will increase and the gain will decrease. A summary of these results is given in the Fig. 24 where the gain and scan angle are shown. Up to a $5 \mathrm{~mm}$ offset, the gain is quite stable $(27.5 \mathrm{~dB}-28.5 \mathrm{~dB})$. A good agreement is achieved between simulation with CST Microwave Studio (Dot curve) and measurement (solid curve).

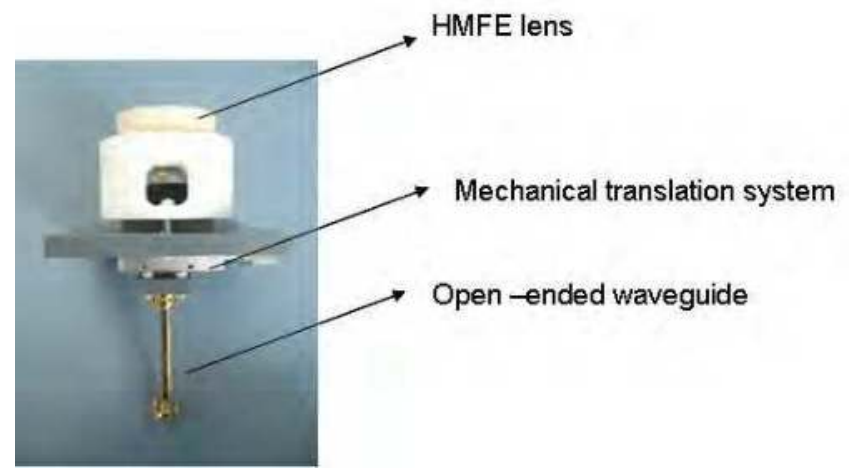

Fig. 22. A 9 - shells $60 \mathrm{~mm}$ diameter HMFE lens associated with a off-axis source to scan the beam

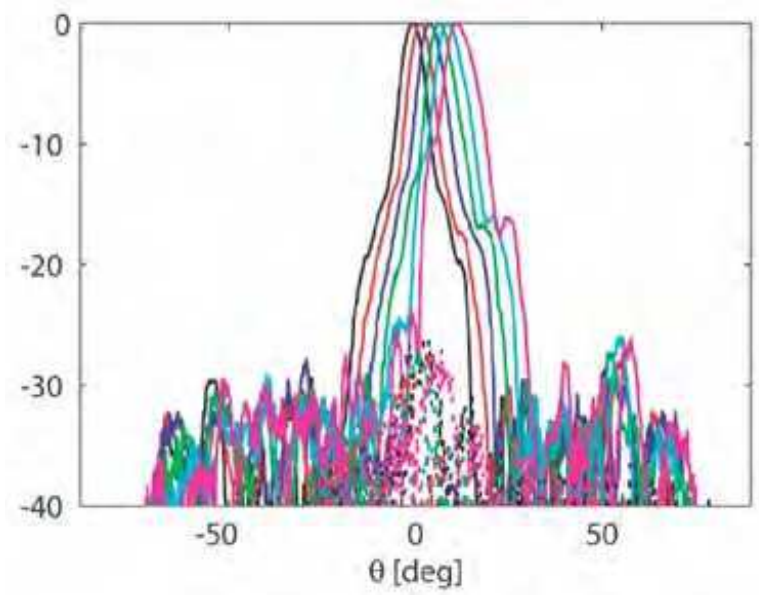

Fig. 23. A 9 - shells $60 \mathrm{~mm}$ diameter HMFE lens associated with a off-axis source to scan the beam - Measured radiation patterns at $77 \mathrm{GHz}$ for 5 source positions ( 1 to $5 \mathrm{~mm}$ ) 


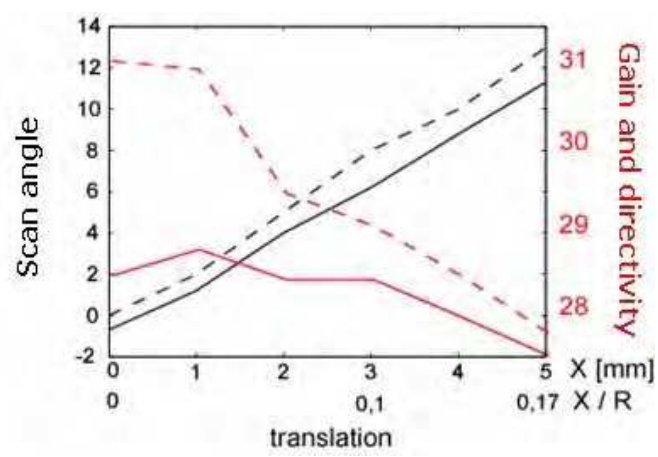

Fig. 24. A 9 - shells $60 \mathrm{~mm}$ diameter HMFE lens associated with a off-axis source to scan the beam - Measured gain and scan angle are compared with simulation results (CST Microwave Studio)

The last results show that is possible to have high gain antenna and beam scanning capability when a HMFE lens is fed with only one feeder. We decided to look what it happens if several sources are associated with such a lens.

\subsection{Beam shaping capability with an HMFE lens}

HMFE lens and a sources array - principle

For the reconfigurable antenna in $\mathrm{W}$ band $(77 \mathrm{GHz})$, the 9-shells $60 \mathrm{~mm}$ diameter HMFE lens is fed by 9 open-ended waveguides placed along the $\mathrm{H}$ plane (Fig 25). All simulations have been done using CST Microwave Studio at $77 \mathrm{GHz}$. If only one waveguide feeds the lens, a directive pattern is achieved with a plane wave at the lens output (Fig. 26 right). If the lens is fed by the 9 waveguides, a sectorial beam is obtained (Fig. 26 left). So, it becomes easy to reconfigure the antenna directivity changing only the alimented source number (Fuchs et al., 2007, c), (Lafond et al., 2008), (Lafond et al., 2009). It is important to note that a sectorial radiation pattern is obtained without any phase shifter. It is a main advantage in millimeter waves, because these devices are often scarce and expensive. The electric fields of each source that feeds the lens are added to obtain the sectorial radiation pattern. Obviously, an amplitude and phase tapering can be applied between sources to obtain another kind of radiation pattern. But in this case, amplifiers and phase shifters have to be added in the feeding line network.

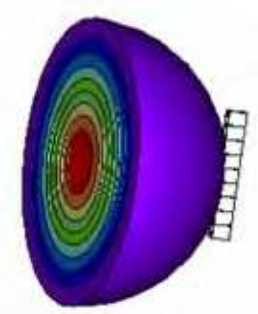

Fig. 25. A 9 - shells $60 \mathrm{~mm}$ diameter HMFE lens associated with a 9 sources array to shape the beam 

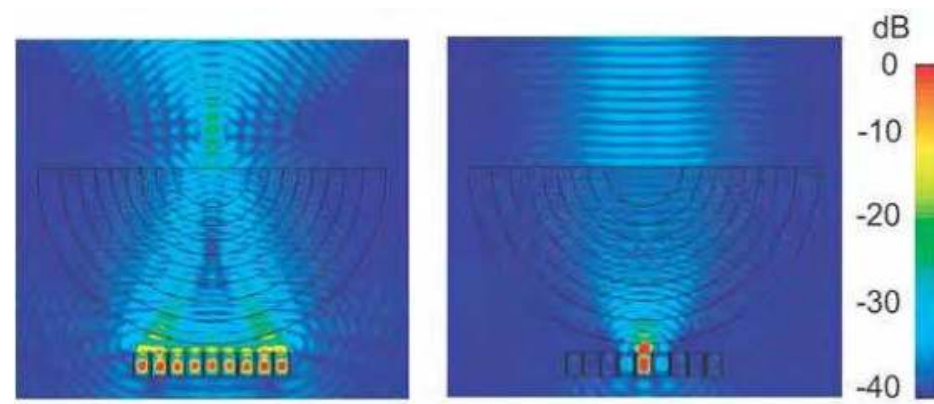

Fig. 26. A 9 - shells $60 \mathrm{~mm}$ diameter HMFE lens associated with a sources array to shape the beam - left : A sectorial pattern is achievd if several sources feed the lens, right : A directive pattern is achieved if only one source feed the lens

HMFE lens and a sources array - Simulation results at $77 \mathrm{GHz}$

We show (Fig. 27) the achieved radiation patterns for different configurations when 1, 3, 5, 7 or 9 waveguides feed the lens. The directivity can be modified between 20 and $31 \mathrm{dBi}$. More the number of sources is high and more we obtain a wide beam (Fig. 28). With this configuration, the beam width in the $\mathrm{H}$ plane is comprised between $5^{\circ}$ ( 1 fed source) and $70^{\circ}$ (9 fed sources).

Furthermore, in this case, for the E plane, the beam width pattern is always narrow thanks to the focusing capability of the lens. But it could be possible to shape the radiation pattern in both $\mathrm{H}$ and $\mathrm{E}$ planes simultaneously using a 2D sources array.

Thus, an easy reconfigurable antenna can be optimized by using only switches to control the number of active sources.

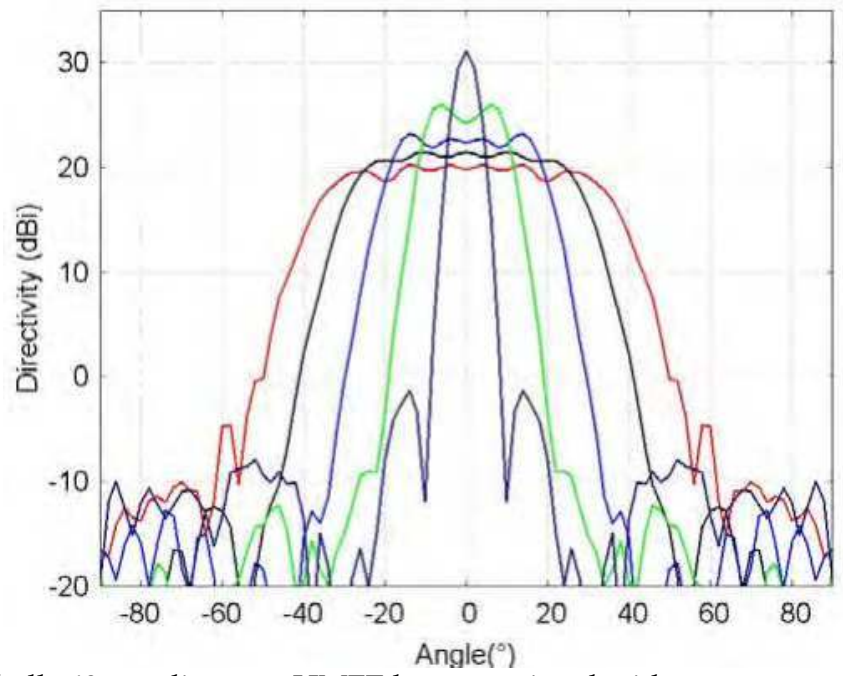

Fig. 27. A 9 - shells $60 \mathrm{~mm}$ diameter HMFE lens associated with a sources array to shape the beam - Simulated radiation patterns when 1, 3, 5, 7 or 9 waveguides feed the lens 


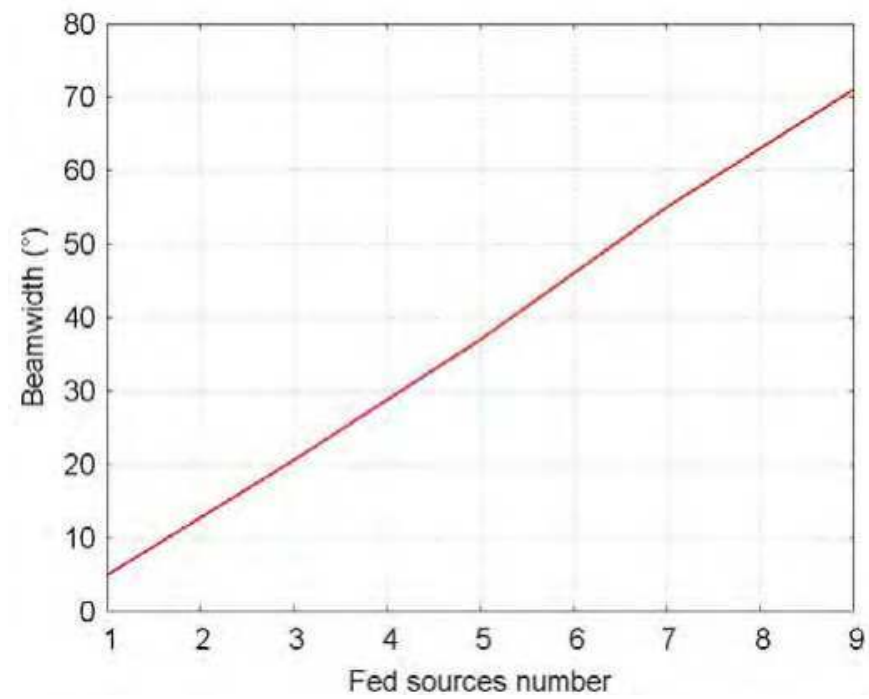

Fig. 28. A 9 - shells $60 \mathrm{~mm}$ diameter HMFE lens associated with a sources array to shape the beam - Simulated beam width versus the fed sources number in the array

Besides, this antenna system also allows having beam scanning properties. Indeed, for example, if a 3 sources group is considered and feeds the lens, the radiation pattern can scan if one moves the fed sources group (Fig. 29). An off-axis sectorial beam is shown because many sources feed the lens simultaneously (Fig. 30).

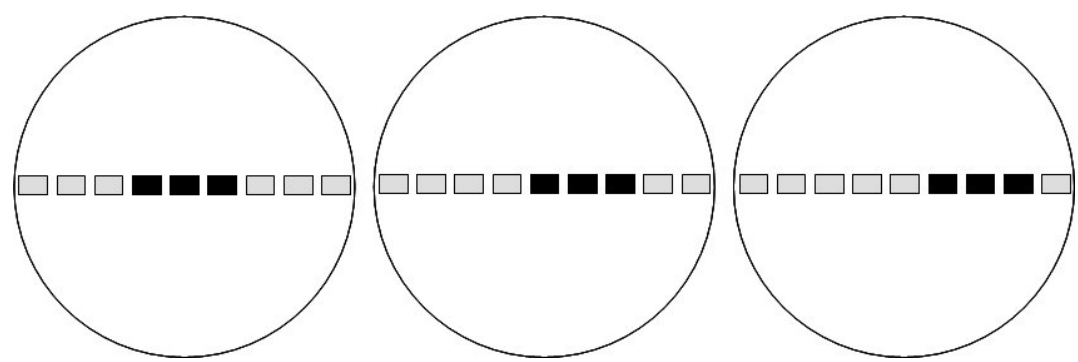

Fig. 29. A 9 - shells $60 \mathrm{~mm}$ diameter HMFE lens associated with a fed,sources group that moves under the lens

HMFE lens and an active sources array - Measured results at $24 \mathrm{GHz}$

In this section, an active sources array is considered and feed the lens to validate the radiation pattern agility presented before. This active prototype is based on the active HPBW reconfigurable antenna shown in the section 3.3. This multilayer printed antenna array is composed of four slot coupled patches and each of them is fed via a LNA amplifier switch (Fig. 31a). First, the passive multilayer printed antenna fed the 9-shells HMFE lens to simulate the global design (Fig. 31b). 


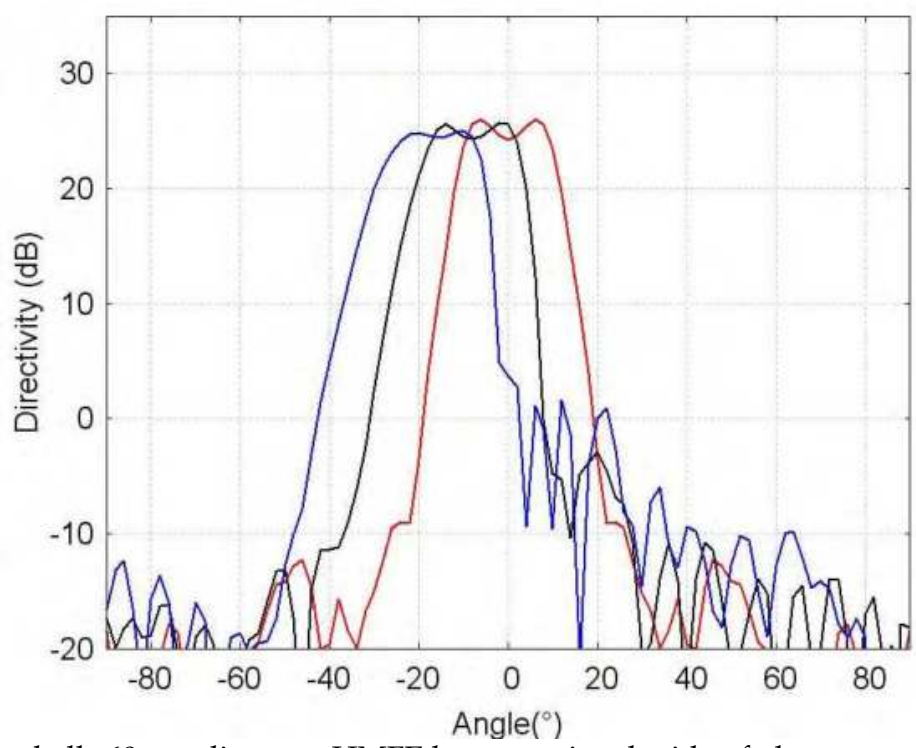

Fig. 30. A 9 - shells $60 \mathrm{~mm}$ diameter HMFE lens associated with a fed,sources group that moves under the lens - Simulated off axis sectorial radiation patterns

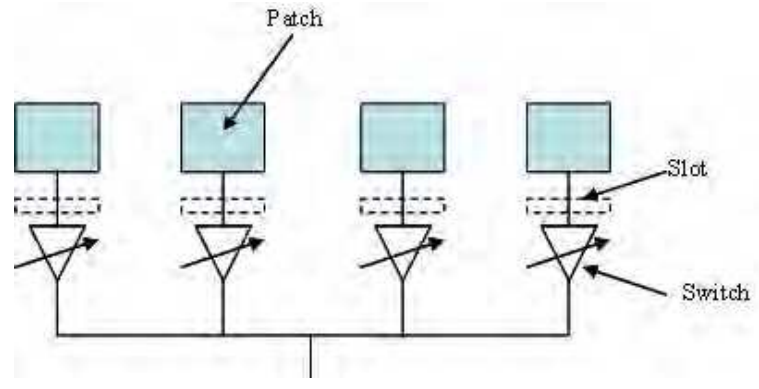

(a)

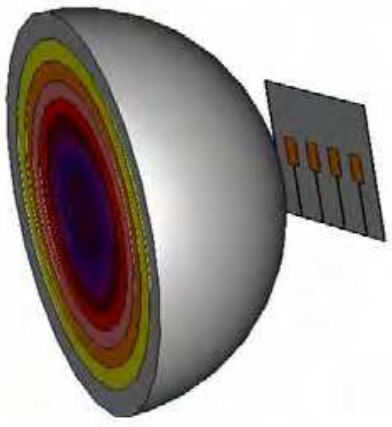

(b)

Fig. 31. (a) The active HPBW reconfigurable antenna based on multilayer printed antennas and switches, (b) Association with the HMFE lens

Two configurations are considered in simulation : two fed patches to obtain a directive pattern and four fed patches to obtain a sectorial one. The simulated radiation patterns are shown in Fig. 32 for both cases. The measured radiation patterns are shown on Fig. 33 and are in good agreement with simulation results. If the two central patches feed the lens, a directive pattern is achieved with a $25^{\circ}$ beam width and a $22.5 \mathrm{~dB}$ gain. If all the patches feed the lens, a sectorial pattern is obtained with a $58^{\circ}$ beam width and a $19 \mathrm{~dB}$ gain. The beam in the E plane is narrow thanks to the focusing capacity of the lens. 


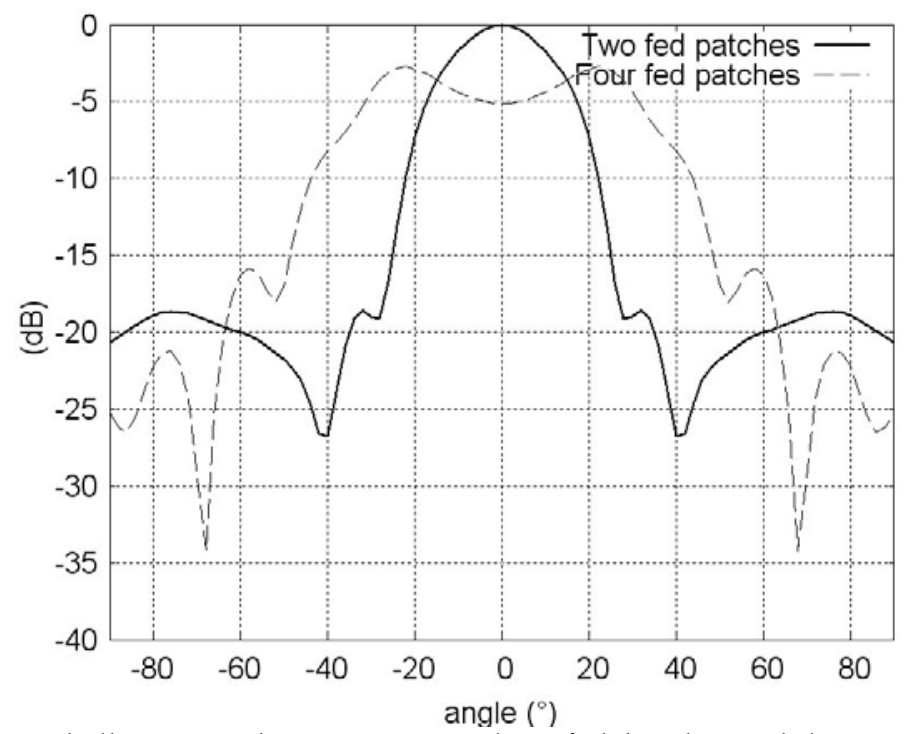

Fig. 32. A 9 - shells $60 \mathrm{~mm}$ diameter HMFE lens fed by the multilayer printed array Simulated radiation patterns for two configurations

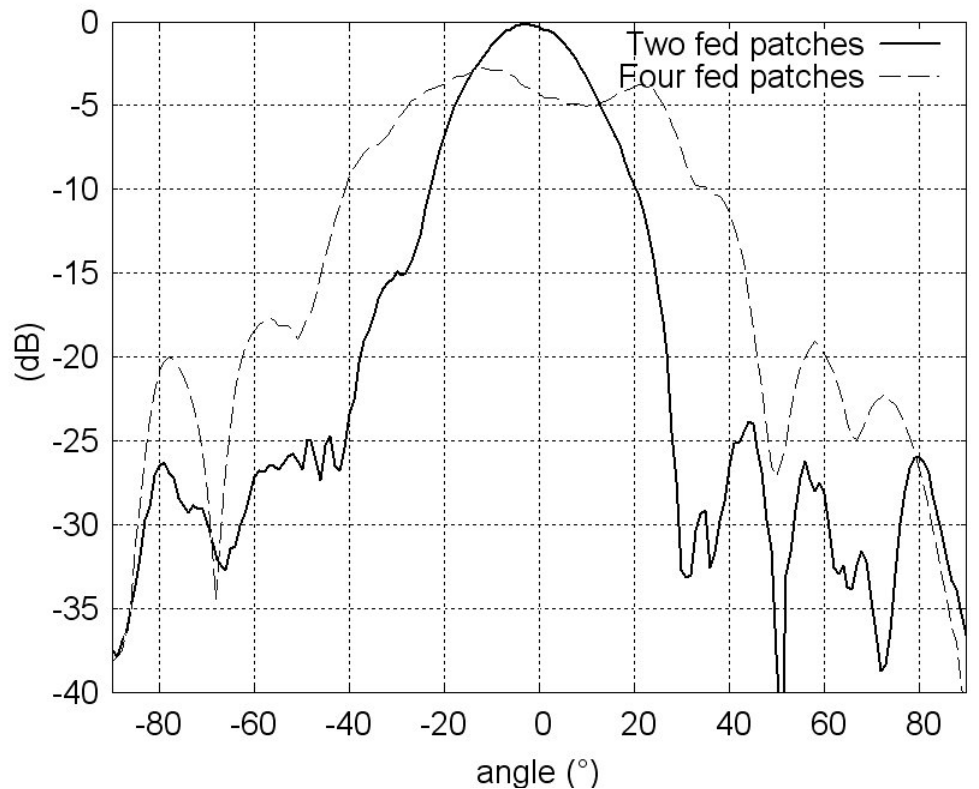

Fig. 33. A 9 - shells $60 \mathrm{~mm}$ diameter HMFE lens fed by the multilayer printed array Measured radiation patterns for two configurations 
All these results show that is possible to obtain a reconfigurable radiation pattern antenna based on a HMFE lens fed by an active sources array. A Sectorial radiation pattern for example can be improved without phase shifters but with only RF switches, that is an advantage because millimetre wave phase shifter are often expensive and have bad performances in term of losses.

\section{Conclusions}

In the section 2 of this chapter, the potential of the Butler matrix system has been demonstrated for the design of active multibeam antennas in millimetre waves. But, metallic and dielectric losses in the feeding network of the Butler matrix induce a quite low efficiency Currently, works are investigated to design a such system using Substrate Integrated Waveguide to improve the gain and the efficiency.

In the section 3, an active tunable HPBW printed antenna has been demonstrated at $24 \mathrm{GHz}$. This prototype allows to vary the half-power beamwidth of the antenna by changing the number of fed patches in the array. To achieve this result, the design of a switch based on a FET transistor has been proposed. The matching of this antenna is obtained whatever the number of fed patches by modifying the characteristic impedance of a quarter wavelength transformer.

Finally, authors have shown an innovative antenna system based on inhomogeneous lens (half Maxwell Fish Eye lens) and fed by several sources. With this antenna concept, it is possible to obtain beam steering and beam shaping capabilities without phase shifters to improve gain and efficiency.

\section{References}

Wenger, J. (2005). 'Automotive radar - Status and perspectives', in Proc. IEEE Compound Semiconductor Integrated Circuit Symposium, 2005.

Butler, J \& Lowe, R. (1961). ‘Beam-forming matrix simplifies design of electrically scanned antennas', Electronic Design, Vol. 9, pp. 170-173, April 1961.

Blass, J 'Multi-directional antenna : new approach top stacked beams', IRE International Convention record, Pt. 1, pp. 48-50, 1960.

Rotman, W \& Turner, R. F. (1963) 'Wide-angle microwave lens for line source applications', IEEE Trans. Antennas Propag., Vol. 11, No. 6, pp. 623-632, November 1963.

Schulwitz, L \& Mortazawi, A. (2006). 'A New Low Loss Rotman Lens Design for Multibeam Phased Arrays', in Proc. IEEE MTT-S Int. Microwave Symp. Dig., pp. 445-448, June 2006.

Baek, C-W \& al. (2003). 'A V-band micromachined 2-D beam-steering antenna driven by magnetic force with polymer-based hinges', IEEE Trans. Microw. Theory Tech., Vol. 51, No. 1, pp. 325-331, January 2003.

Cetiner, B.A \& al. (2003). 'Monolithic integration of RF MEMS switches with a diversity antenna on PCB substrate', IEEE Trans. Microw. Theory Tech., Vol. 51, No. 1, pp. 332-335, January 2003.

Popovic, D \& Popovic, Z. (2002). 'Multibeam Antennas With Polarization and Angle Diversity', IEEE Trans. Antennas Propag., pp. 651-657, Vol. 50, No. 5, May 2002. 
Wu, X; Eleftheriades, G.V. \& Van Deventer-Perkins, T.E. (2001). 'Design and characterization of single- and multiple-beam mm-wave circularly polarized substrate lens antennas for wireless communications', IEEE Trans. Microw. Theory Tech., Vol. 49, No. 3, pp. 431-441, March 2001.

Lafond, O. \& Himdi, M. (2002). 'Multibeam antenna in millimetre waves', in Proc. of the 32nd European Microwave Conference (EuMC), Milan, September 2002.

Lafond, O.; Himdi, M. \& Daniel, J.P. (1999). 'Aperture coupled microstrip patch antenna with thick ground plane in millimeter-waves,' Electronics Letters, Vol. 35, no. 17, pp. 1394-1396, August. 1999.

Lafond, O.; Himdi, M.; Daniel, J.P \& Haese-Rolland, N. (2002). ( 'microstrip / Thick-slot / microstrip transitions in millimeter-waves,' Microwave and Optical Technology Letters, Vol. 34, Issue 2, pp. 100-103, July 2002.

Lafond, O.; Himdi, M; Vendier, O. \& Cailloce, Y. (2005). 'Thick-slot transition and antenna arrays in the Q band,' Microwave and Optical Technology Letters, Vol. 44, Issue 1, pp. 24-29, January. 2005.

www.macom.com/Products/switches.htm

Rebeiz, G. M. (2003). 'RF MEMS: Theory, Design and Technology,' Wiley- Interscience, February 2003.

www.quinstar.com/qwz electromechanical waveguide switches.html

Caillet, M.; Lafond, O. \& Himdi, M. (2006). 'A Directivity Diversity Microstrip Antenna Array in Millimeter Wave,' Microwave Opt. Tech. Letters, Vol. 48, No. 6, pp. 11901194, June 2006.

Caillet, M. (2006). 'Etude et Conception d'un système Radar Courte Portée et d'Antennes Reconfigurables en Bande Millimétrique,' Thèse de l'Université de Rennes 1, 2006.

Luneburg, R.K. (1944). 'Mathematical theory of optics,' Providence, Rhode Island, Brown University Press, 1944.

Lafond, O; Himdi, M; Rondineau, S. \& Fuchs, B. (2007) . 'Lentilles inhomogènes à gradient d'indice de type œil de Poisson de Maxwell, système d'antennes et applications correspondantes', French Patent $n^{\circ} 2888407$ (2007).

Fuchs, B; Lafond,O; Rondineau, S \& Himdi, M. (2006). 'Design and characterization of half Maxwell fish-eye lens antennas in millimeter waves,' IEEE Trans. Microwave Theory Tech., vol. 54, no. 6, pp. 2292-2300, June 2006.

Fuchs, B; Le Coq, L; Lafond,O; Rondineau, S \& Himdi, M. (2007), "Design Optimization of Multi-Shell Luneburg Lenses," IEEE Transactions on Antennas and Propagation, vol.55, n², pp. 283- 289, Feb 2007.

Fuchs, B. (2007). 'Lentilles stratifies et Sources réelles associées - Analyses théoriques et validations expérimentales en Ondes Millimétriques', Thèse de l'Université de Rennes 1, 2007.

Fuchs, B; Lafond,O; Rondineau, S \& Himdi, M \& Le Coq, L. (2007). ‘Off-Axis Performances of Half Maxwell Fish-Eye Lens Antennas at 77GHz,' IEEE Transactions on Antennas and Propagation, vol.55, n², pp. 479- 482, Feb 2007.

Fuchs, B; Palud, S; Lafond,O; Rondineau, S; Himdi, M \& Le Coq, L,: 'Système antennaire dont le diagramme de rayonnement est reconfigurable parmi des diagrammes de rayonnement sectoriels et directifs, et dispositif émetteur/ou récepteur correspondant', French Patent $n^{\circ}$ R13414FR (2007). 
Lafond,O; Caillet, M; Fuchs, B; Palud, S; Himdi, M ; Rondineau, S \& Le Coq, L. (2008) 'Millimeter Wave Reconfigurable Antenna Based on Active Printed Array and Inhomogeneous Lens, 'EUMW 2008, Amsterdam, October 2008.

Lafond, O; Fuchs, B; Palud, S; Caillet, M; Himdi, M ; Rondineau, S \& Le Coq, L. (2009), 'Reconfigurable antenna in mm-waves based on stratified lens and sources array,' EUCAP 2009, Berlin, March 2009. 


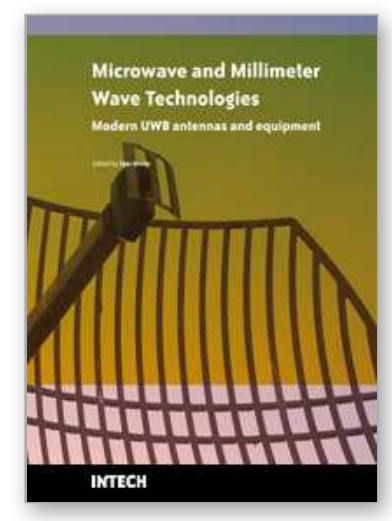

\section{Microwave and Millimeter Wave Technologies Modern UWB antennas and equipment}

Edited by Igor Mini

ISBN 978-953-7619-67-1

Hard cover, 488 pages

Publisher InTech

Published online 01, March, 2010

Published in print edition March, 2010

\section{How to reference}

In order to correctly reference this scholarly work, feel free to copy and paste the following:

Olivier Lafond, M. Caillet, B. Fuchs and M. Himdi (2010). Reconfigurable Radiation Pattern Antennas in mmWaves, Microwave and Millimeter Wave Technologies Modern UWB antennas and equipment, Igor Mini (Ed.), ISBN: 978-953-7619-67-1, InTech, Available from: http://www.intechopen.com/books/microwave-andmillimeter-wave-technologies-modern-uwb-antennas-and-equipment/reconfigurable-radiation-patternantennas-in-mm-waves

\section{INTECH}

open science | open minds

\section{InTech Europe}

University Campus STeP Ri

Slavka Krautzeka 83/A

51000 Rijeka, Croatia

Phone: +385 (51) 770447

Fax: +385 (51) 686166

www.intechopen.com

\section{InTech China}

Unit 405, Office Block, Hotel Equatorial Shanghai

No.65, Yan An Road (West), Shanghai, 200040, China

中国上海市延安西路65号上海国际贵都大饭店办公楼405单元

Phone: +86-21-62489820

Fax: +86-21-62489821 
(C) 2010 The Author(s). Licensee IntechOpen. This chapter is distributed under the terms of the Creative Commons Attribution-NonCommercialShareAlike-3.0 License, which permits use, distribution and reproduction for non-commercial purposes, provided the original is properly cited and derivative works building on this content are distributed under the same license. 